Periodica Polytechnica Civil Engineering, 64(1), pp. 188-197, 2020

\title{
Cutting Characteristics and Layout of Pre-cutting Machine Cutter
}

\author{
Xuhui Zhang ${ }^{1}$, Jianmin $\mathrm{Li}^{1 *}$, Yimin Xia², Laikuang Lin², Mi Li', Li Chen³ \\ 1 College of Engineering and Design, Hunan Normal University, Changsha, 410081, China \\ 2 State Key Laboratory of High Performance Complex Manufacturing, Central South University, Changsha, 410083, China \\ ${ }^{3}$ China Railway Construction Heavy Industry Co., LTD, Changsha, 410100, China \\ *Corresponding author, e-mail: ljmdzyx@hunnu.edu.cn
}

Received: 25 November 2019, Accepted: 02 January 2020, Published online: 29 January 2020

\begin{abstract}
The pre-cutting machine is becoming valued due to its ability to effectively prevent surface settlement and reduce vibration in tunnel construction. To obtain the cutting characteristics and layout of pre-cutting machine cutter, the cutting tests by the pre-cutting machine cutter are conducted and the cutting laws are also studied. The research results show that the cutting force rather than normal force and side force is responsible for the rock breaking. With the increase of the cutting depth and cutting spacing, the cutting forces increase generally. But for the little value of cutting spacing, the cutting force can not increase continuously when the cutting depth increase to a relatively large value. Furthermore, for a given cutting depth, the cutting force will keep at an approximate constant rather than continuous increase with the increase of the cutting spacing when the cutting spacing increases to a relatively large value. The specific energy decreases nonlinearly with the increase of cutting depth and the decrease of specific energy is not significant when the cutting depth is more than $12 \mathrm{~mm}$. Moreover, there exists an optimal cutting spacing for a given cutting depth. To maintain a desirable cutting efficiency, the ratio of cutting spacing to cutting depth should be controlled between 1 and 2 . Finally, the layout plan of the pre-cutting machine cutter is proposed based on the research results and is applied in the actual manufacturing of the pre-cutting machine.
\end{abstract}

\section{Keywords}

pre-cutting machine, cutting depth, cutting spacing, layout

\section{Introduction}

The mechanical pre-cutting method can be applied to different strata $[1,2]$ which is suitable for excavation projects with a relatively short excavation distance and a small excavation scope. The mechanical pre-cutting method is mainly carried out by the pre-cutting machine. For soil strata, pre-cutting method means that a certain broadband groove is first cut with the pre-cutting machine cutters before tunnel excavation. Meanwhile, concrete is injected with the appropriate equipment installed on the pre-cutting machine to form a concrete supporting layer, as shown in Fig. 1(a). Mechanical excavation can be started when the strength of the concrete supporting layer has reached a certain degree, and the concrete supporting can be performed for a second time, if necessary, after the mechanical excavation has been started. This can effectively prevent surface settlement and guard against landslides in the construction process.

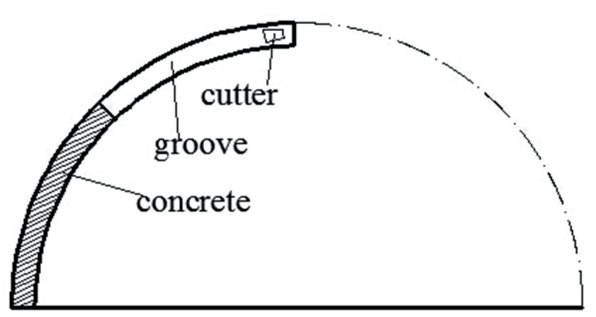

(a) Pre-cutting machine used in soil strata

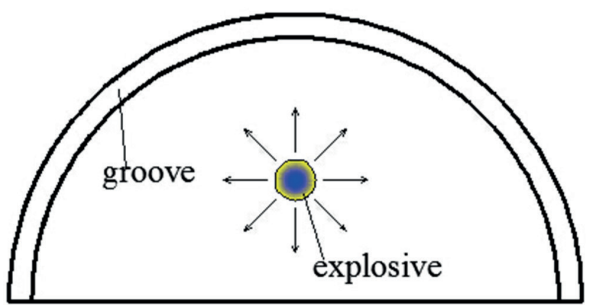

(b) Pre-cutting machine used in rock strata

Fig. 1 Pre-cutting methods using pre-cutting machine within two kinds of strata 
For rock strata, pre-cutting method means that a certain broadband groove is also cut with the pre-cutting machine cutters before tunnel excavation, as shown in Fig. 1(b). Then, the tunnel face is excavated through the drilling and blasting method and further supporting measures may be taken to prevent landslides. This can effectively eliminate the damage caused by drilling and blasting to the surrounding rock, and reduce noise and vibration.

Mechanical pre-cutting method was first introduced in the USA [2]. In 1950, the Silas Mason Co. introduced the mechanical pre-cutting method successfully as a tunneling technique to the construction of twelve circular tunnels with excavated diameters in the order of $10 \mathrm{~m}$ through chalk, at the Fort Randall Reservoir Project on the Missouri River at Pickstown, S. Dak., U.S.A. Then in 1969, the French engineer adopted this method to successfully solve the problem of blasting vibration in the construction of rock tunnels in urban areas, which led the method to regain focus. Since then, this method has been evolved and developed in France and three generations of pre-cutting machines have been developed. In the early 1980s, Japan also introduced the technology of mechanical pre-cutting method and the advanced support construction technology which was suitable for the situation of Japan [3]. Then, in 1991, the construction test was carried out in Japan with the curve shaped pre-cutting machine. In China, the mechanical pre-cutting method and pre-cutting machine were developed in the 1980 s to 1990 s. In view of the situation of tunnel engineering in China at that time, China Railway Construction Research Institute proposed the research scheme of the pre-cutting machine and its construction technology based on soil and soft rock tunnels [4]. The design and trial manufacturing of the working head of the pre-cutting machine were completed at that time, but the research was suspended due to various reasons.

Recently, the pre-cutting machine is becoming valued by many construction enterprises due to its ability to effectively prevent surface settlement and reduce vibration in the tunnel construction, which will greatly promote the development of the mechanical pre-cutting method and pre-cutting machine.

For the mechanical pre-cutting method and pre-cutting machine, there have been a few reports mainly covering the following research results. Walsum [2] introduced the development course and construction method of the mechanical pre-cutting method, and analyzed the advantages which make this method different from other tunnel excavation methods. Tonon [5] studied the mechanism of stratum deformation during the construction with mechanical pre-cutting method; Du et al. [6] explored the mechanism of controlling the deformation of soft surrounding rock after the construction with mechanical pre-cutting method. Hao et al. [7] put forward a set of design methods for the pre-cutting machine based on soil mechanics and shield machine design method and analyzed the functions of the 9 sub structures of pre-cutting machine.

Pre-cutting machine mainly uses its cutter driven by the chain to cut the rock and soil continuously. As the pre-cutting machine cutter is the key component for slotting, its working conditions are directly related to the slotting efficiency as well as to the reliability and safety of the pre-cutting machine. Therefore, it is necessary to master the cutting characteristics of the cutter before the design and construction with the pre-cutting machine.

Currently, research on the rock cutting characteristics of the cutter is mainly focused on the tunnel boring machine and coal mining machine. For example, Cho et al. [8] carried out a series of linear cutting tests and investigated the optimum cutting condition of a disc cutter. Geng et al. [9, 10] investigated the dynamic process of rock breaking by normal and edge disc cutters, and obtained the cutting characteristics under different cutting conditions. Zaré and Mikaeil [11] used discrete element method to simulate the rock cutting process by disc cutter and obtained the optimal cutting condition. Liu et al. [12, 13] discovered the rock breaking characteristics with different confining stresses and cutting sequence induced by disc cutter based on indentation tests. Zhang et al. [14] performed a series of rock cutting tests by disc cutter considering the effect of free surface. Baker and Gertsch [15] conducted the rock cutting tests under water by the drag cutter of the shield, and studied the cutter force and cutting efficiency. Xia et al. [16] investigated the cutting force of the drag cutter under different cutting parameters based on the rotary cutting machine. Copur et al. [17] conducted the rock cutting tests by conical pick and studied the cutting performance under different cutting patterns. Qiao et al. [18] established a coal-rock constitutive model with finite element method for rock cutting by conical pick and investigated the rock cutting force. Li et al. [19] studied the rock cutting characteristics of conical pick by discrete element method. Jeong and Jeong [20] provided the rock chip characteristic produced by conical pick based on rock cutting tests. Wang et al. [21] and Li et al. [22] carried out a series of rock cutting tests by conical pick and presented the rock breaking characteristic under different confining stress. 
The above research on the cutting characteristics of the cutter installed on the tunnel boring equipment and coal mining machine is of great value for reference. However, as the cutting mode, cutting conditions and the structures of the pre-cutting machine cutter are different from those of the traditional cutter of the tunnel boring equipment and coal mining machine, the cutting characteristics and cutting rules related above traditional cutter can not be applied to pre-cutting machine cutter directly. Thus, it is very necessary to master the cutting characteristics of the pre-cutting machine cutter to design the structure of the pre-cutting machine cutter head and cutter layout effectively. In this paper, the experiments of cutting rock-like material which replaces the rock with a full-scale pre-cutting machine cutter are carried out through the linear cutting machine, the cutter forces and the specific energy of the pre-cutting machine cutter under different cutting parameters are investigated, and a new kind of layout plan for pre-cutting machine cutters is proposed to provide reference for the design of the pre-cutting machine head and the layout of the cutter.

\section{Experiment setup}

\subsection{Experiment equipment}

The linear cutting machine is presented in Fig. 2. With an overall size of about $5 \mathrm{~m} \times 3.2 \mathrm{~m} \times 3.5 \mathrm{~m}$, the linear cutting machine mainly consists of three parts: hydraulic system, testing system and mechanical cutting system [23].

The hydraulic system can control the cutting device to move in three directions including vertical direction, longitudinal direction and horizontal direction.

The testing system is composed of a three-direction force sensor and a computer with embedded testing software. The three-direction force sensor is installed on the cutting system to collect the cutter force including normal

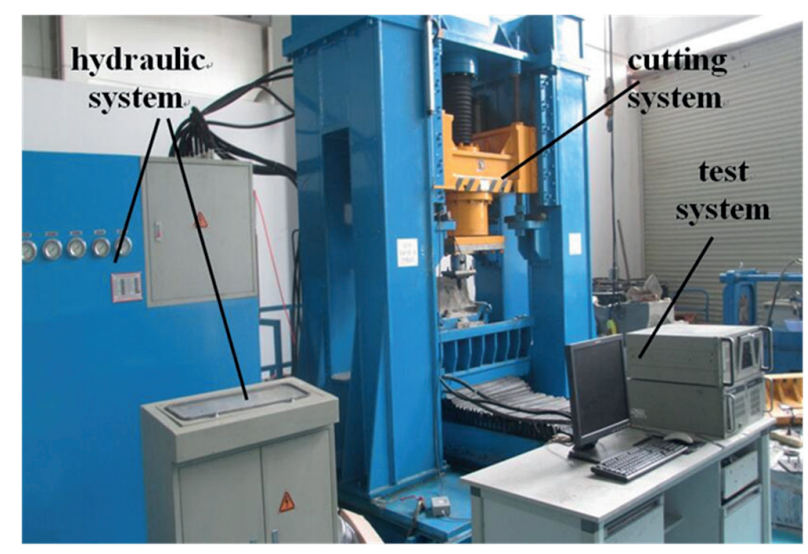

Fig. 2 The linear cutting machine force, cutting force and side force, as shown in Fig. 3(a). Then the computer can display the measured value of cutter force through the embedded testing software.

The mechanical cutting system utilizes the rails with four corners and eight sides to achieve reliability and stability, which enables the system to bear large torque and ensure the rigidity of the cutting mechanism. Meanwhile, the cutting system adopts the positioning mechanism of mechanical screw which can ensure a constant cutting depth. The three-direction force sensor and the pre-cutting machine cutter are mounted on the cutting system through bolts.

\subsection{The pre-cutting machine cutter}

The pre-cutting machine cutter is composed of the hard alloy cutter bit, the cutter body and the cutter base, as shown in Fig. 3(b). The hard alloy with high wear resistance and long service life is welded on the cutter body. This cutter is used in the whole cutting experiments to conduct the cutting tests and its specific geometric parameters are shown as follows: the front angle (B) and lateral edge angle $(\alpha)$ are $120^{\circ}$ and $95^{\circ}$; the width (d) and height (h) of the cutter are $22 \mathrm{~mm}$ and $87 \mathrm{~mm}$, respectively. The meanings of each parameter are shown in Fig. 3(a).

\subsection{Rock sample}

It is difficult to get the same rock as what is cut by the pre-cutting machine in the construction site. Thus, the rock-like material composed of cement and sand is used to replace rock in the cutting tests. According to the construction geological exploration report from a project to be constructed by pre-cutting machine in china, the uniaxial compressive strength of the rock is about $15 \mathrm{MPa}$. Then, the rock-like material was made based on lots of proportioning experiments and mechanical test experiments to

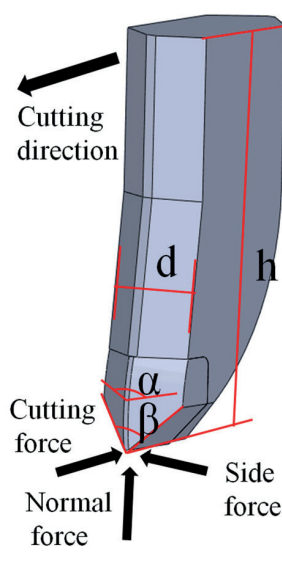

(a) Model picture

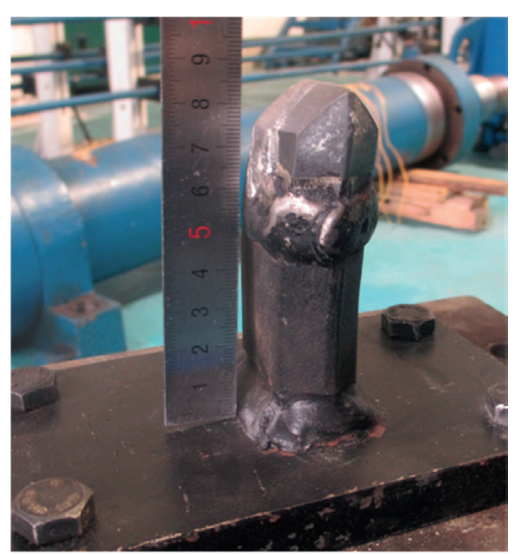

(b) Physical picture
Fig. 3 The pre-cutting machine cutter 
Table 1 Mechanical parameters of rock sample

\begin{tabular}{lc}
\hline Density $\left(\mathrm{kg} \cdot \mathrm{m}^{-3}\right)$ & 1953 \\
\hline Young's modulus $(\mathrm{GPa})$ & 0.85 \\
Uniaxial compressive strength $(\mathrm{MPa})$ & 14.91 \\
Brazilian tensile strength $(\mathrm{MPa})$ & 1.10 \\
\hline
\end{tabular}

match the rock in actual engineering. The size of the rocklike material sample is $470 \mathrm{~mm} \times 470 \mathrm{~mm} \times 300 \mathrm{~mm}$ and its main mechanical parameters are listed in Table 1.

\subsection{Cutting scheme}

The completed sample was put into the steel box and fixed by tightening the bolts. Before cutting tests, multiple cuts of the sample were made at the required cutting depth and cutting spacing to create an original damaged rock surface comparable to that in actual field conditions, as shown in Fig. 4. The cutting speed of the pre-cutting machine cutter is set to $15 \mathrm{~mm} / \mathrm{s}$ in these cutting tests. The cutting depth used during testing is $3,6,9,12,15 \mathrm{~mm}$, and the cutting spacing used during testing is $5,10,15,20,25 \mathrm{~mm}$, as shown in Table 2. The cutter forces and rock chips are collected during cutting process. The specific energy is calculated by Eq. (1), which is used to describe the rock cutting efficiency, and the greater the specific energy is, the lower the cutting efficiency will be [24].

$$
S E=\frac{w}{v_{\mathrm{o}}}=\frac{F_{c} l}{v_{o}}=\frac{F_{c} l \rho}{m},
$$

where $S E$ denotes the specific energy, $w$ denotes the cutting work, $v_{o}$ denotes the rock breaking volume, $F_{c}$ denotes the cutting force, $l$ denotes the cutting stroke, $\rho$ denotes the rock density, $m$ denotes the rock breaking mass.

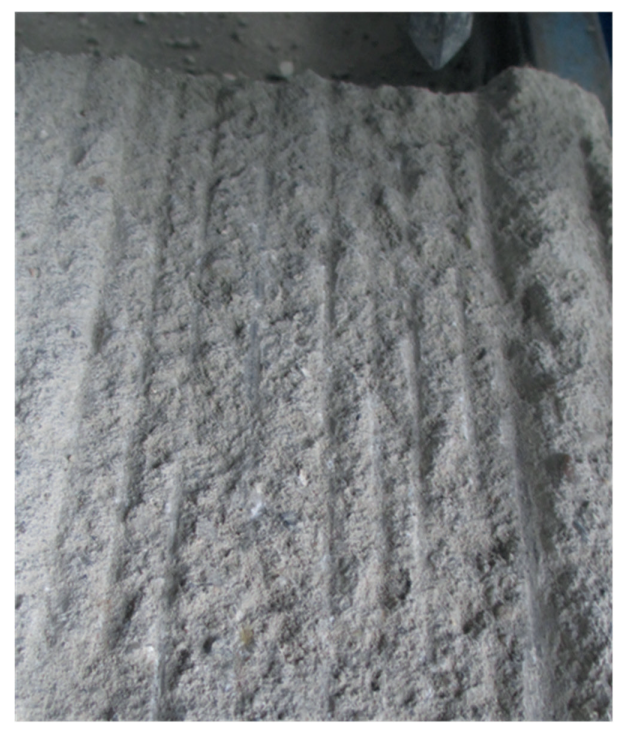

Fig. 4 Original damaged rock surface before cutting
Table 2 Cutting parameters used in cutting tests

\begin{tabular}{lc}
\hline Cutting parameters & Parameter values \\
\hline Cutting depth $(\mathrm{mm})$ & $3,6,9,12,15$ \\
Cutting spacing $(\mathrm{MPa})$ & $5,10,15,20,25$ \\
\hline
\end{tabular}

\section{Experimental results and analysis}

\subsection{Rock cutting process by the pre-cutting machine} cutter

Fig. 5 illustrates the rock breaking process in the time sequence by the pre-cutting machine cutter when the cutting depth and the cutting spacing are $9 \mathrm{~mm}$ and $15 \mathrm{~mm}$ respectively. The fine rock chips are produced around the cutter edge firstly, and some fine rock chips fly away from the rock surface quickly due to the high contact stress between the cutter edge and rock, as shown in Figs. 5(a) and (b). Then a big rock chip can be observed and it will fly towards the right groove produced by previous cutting with the rapid movement of the cutter, as shown in Figs. 5(c) and (d). It indicates that the previous cutting can promote the rock breaking when the cutting spacing is proper at a given cutting depth.

The rock chips with different sizes were collected, as shown in Fig. 6, it can be observed that the number of large rock chip accounts for the smallest proportion. Furthermore, the broken surface of the big rock chip is very uneven and has no obvious friction marks, as shown in Fig. 7. It implies that the breaking mechanism of the big rock chip produced is dominated by tensile failure rather than shear failure.

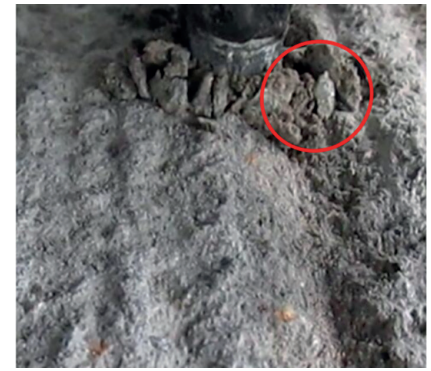

(a) Time $=2.5 \mathrm{~s}$

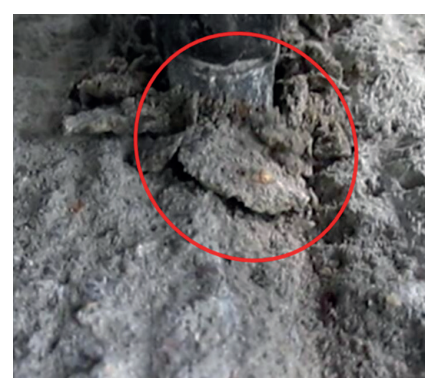

(c) Time $=4.5 \mathrm{~s}$

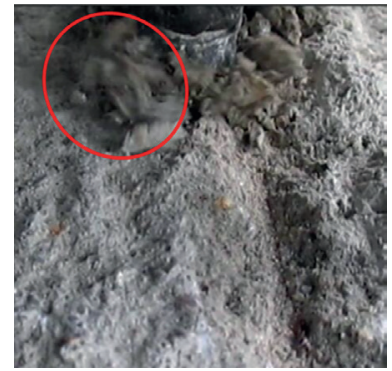

(b) Time $=3.5 \mathrm{~s}$

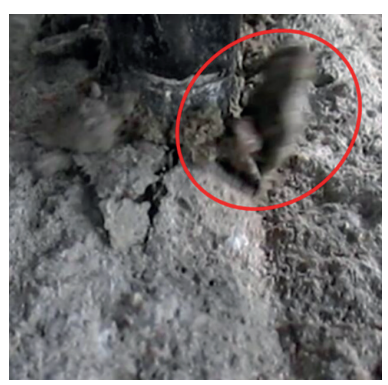

(d) Time $=5.5 \mathrm{~s}$
Fig. 5 Rock breaking process induced by pre-cutting machine cutter 


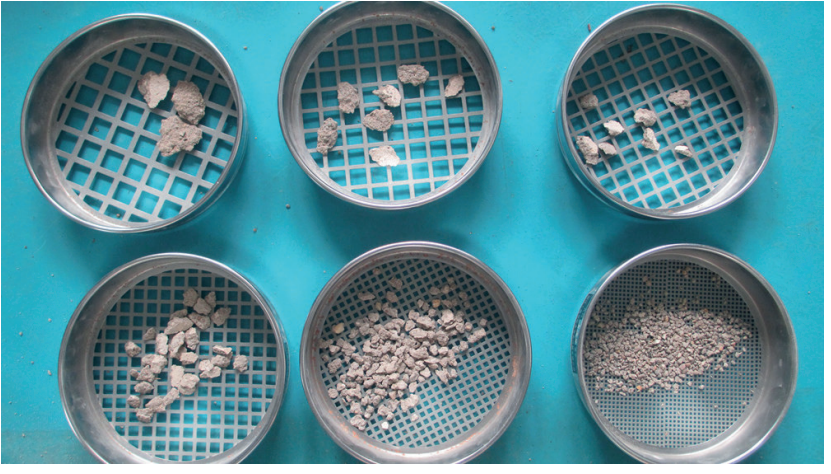

Fig. 6 Rock chips produced by pre-cutting machine cutter

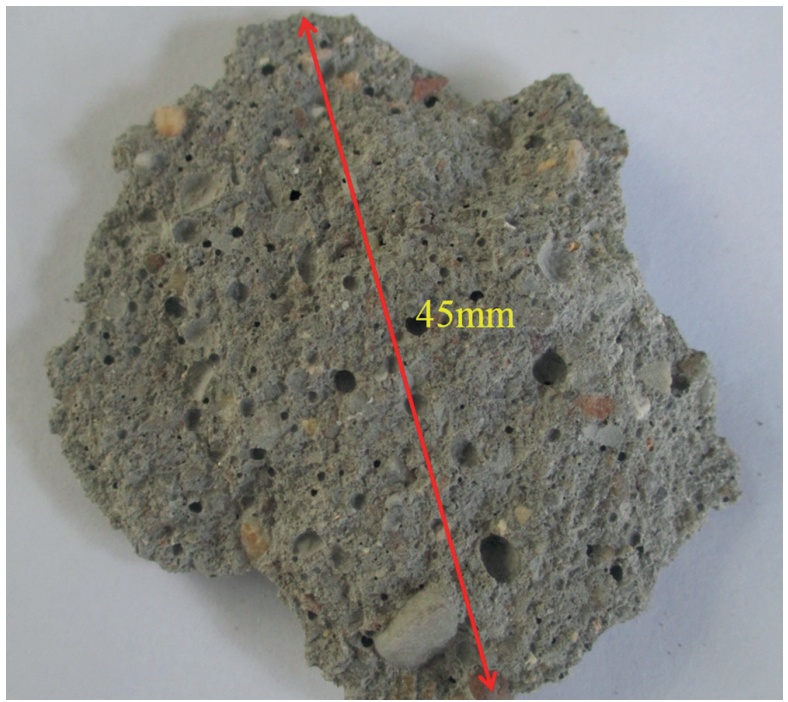

Fig. 7 Big rock chip produced by pre-cutting machine cutter

The cutter forces during cutting process are shown in Fig. 8. The cutter forces present an obvious fluctuating change with the increase of the cutting time. Meanwhile, the cutting force, the normal force and the side force increase and decrease simultaneously with the same change trend. The side force of the cutter fluctuates around zero with the increase of cutting time due to the random rock breaking on both sides of the cutter edge, indicating the direction of the side force changes with cutting time. However, the direction of the cutting force and normal force remains unchanged. Additionally, the cutting force is obviously greater than the side force and the normal force. It implies that the cutting force is mainly responsible for rock breaking for the pre-cutting machine cutter. Thus, only cutting force is investigated in the following sections in this paper. It should be noted that the peak values of the cutter forces correspond to the generation of big rock chip $[18,25]$, as presented by three ovals in Fig. 8, causing the cyclic occurrence of large and small rock chips, which is consistent with the above analysis about rock chips.

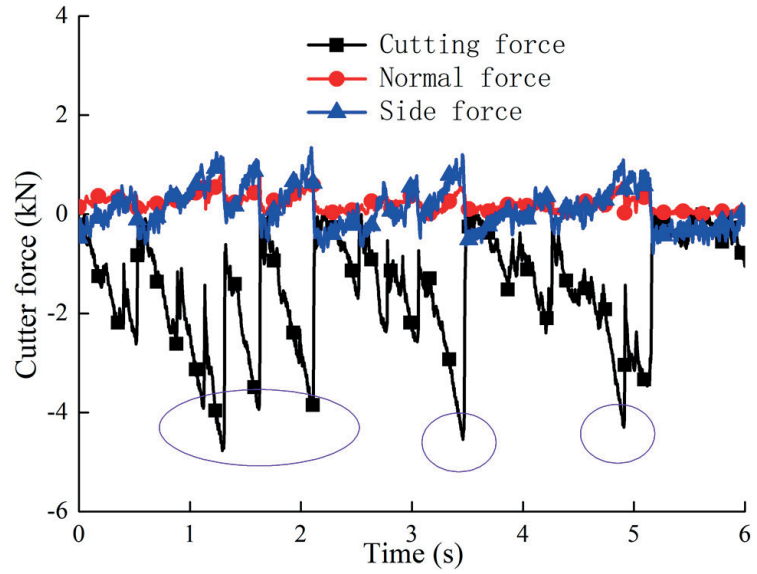

Fig. 8 Cutter forces with time when the cutting depth is $9 \mathrm{~mm}$ and the cutting spacing is $15 \mathrm{~mm}$

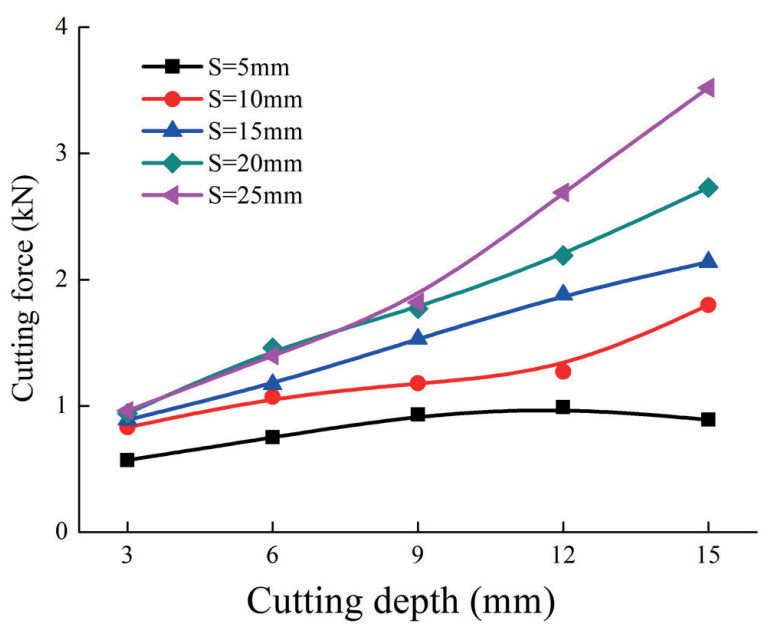

Fig. 9 The relationship between average cutting force and cutting depth

\subsection{Influence of cutting depth on cutting force}

The relationship between the average cutting force and cutting depth is shown in Fig. 9. Overall, the cutting force increases almost linearly with the increase of the cutting depth, regardless of the cutting spacing. Furthermore, it can be concluded that the large cutting spacing corresponds to a relatively large gain in the magnitude of cutting force compared with the small cutting spacing. For example, in the case that the cutting spacing equals to $10 \mathrm{~mm}$, the cutting force increases from $0.83 \mathrm{kN}$ to $1.80 \mathrm{kN}$ as the cutting depth increases from $3 \mathrm{~mm}$ to $15 \mathrm{~mm}$, corresponding to little gain in the magnitude of cutting force, approximately $0.97 \mathrm{kN}$. However, under the circumstance that the cutting spacing equals to $20 \mathrm{~mm}$, the cutting force increases from $0.96 \mathrm{kN}$ to $3.52 \mathrm{kN}$ when the cutting depth increases from $3 \mathrm{~mm}$ to $15 \mathrm{~mm}$, corresponding to a large gain in the magnitude of cutting force, approximately $2.56 \mathrm{kN}$. In other words, the larger the cutting spacing is, the increase of cutting force caused by the cutting depth is greater. 
The main reason for this is that there is a strong interaction between two cutting grooves when the cutting depth is narrow. Thus, the front cuts have a great influence on the subsequent cutting processes, leading to a small increase of cutting force caused by the increase of the cutting depth. On the contrary, when the cutting spacing is wide, the increase of the cutting depth can increase the cutting force obviously as it only exists a slight interaction between two cutting grooves, resulting in a large increase of cutting force caused by the cutting depth. Additionally, when the cutting spacing is $5 \mathrm{~mm}$, the cutting force first increases and then decreases with the increase of the cutting depth. It can also be explained by the strong interaction between the cutting grooves that only a little bit of rock material is cut away by the cutter due to the narrow cutting spacing although the cutting depth increases to a large value with $15 \mathrm{~mm}$, causing a decrease in cutting force.

\subsection{Influence of cutting spacing on cutting force}

The changing trend of the cutting force with the cutting spacing is illustrated in Fig. 10. It can be found that there is a positive correlation between the cutting force and the cutting spacing as the cutting depth is at a large value, i.e. $12 \mathrm{~mm}$ and $15 \mathrm{~mm}$. However, when the cutting depth is at a little value, such as at $3 \mathrm{~mm}, 6 \mathrm{~mm}$ and $9 \mathrm{~mm}$, the cutting force first increases and after that it remains at an approximate constant with the increase of the cutting spacing. It can be revealed that, for a given cutting depth, the rock ridge between two cutting grooves shows breaking excessively, followed by breaking properly, and then no breaking with the increase of the cutting spacing. When the values of the cutting depth are $3 \mathrm{~mm}, 6 \mathrm{~mm}$ and $9 \mathrm{~mm}$, the rock

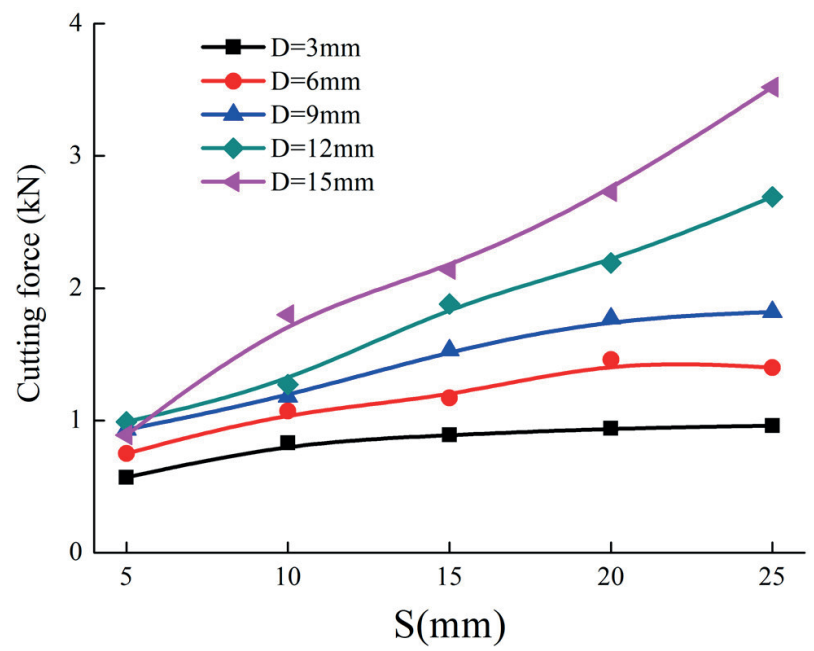

Fig. 10 The relationship between average cutting force and cutting spacing ridge can not be cut away as the cutting spacing increases to $20 \mathrm{~m}$. Therefore, the cutting force keeps at an approximate constant with the further increase of cutting spacing since there is no mutual interaction between adjacent cutting grooves. However, when the cutting depth equals to a large value, such as $12 \mathrm{~mm}$ and $15 \mathrm{~mm}$, there is always mutual interaction between adjacent cutting grooves as the cutting spacing varies from $5 \mathrm{~mm}$ to $25 \mathrm{~mm}$, leading to a continuous increase in cutting force with the increase the cutting spacing.

According to the above analysis, it can be concluded that both the cutting depth and the cutting spacing have a positive impact on the increase of the cutting force generally. However, for the little value of the cutting spacing, such as $5 \mathrm{~mm}$ in this paper, the cutting force first increases and then decreases with the increase of the cutting depth due to strong interaction between adjacent cutting grooves. Meanwhile, for the little value of the cutting depth, such as $3 \mathrm{~mm}, 6 \mathrm{~mm}$ and $9 \mathrm{~mm}$ in this paper, the cutting force increases first and then keeps at an approximate constant with the increase of the cutting spacing since there is no mutual interaction between adjacent cutting grooves when the cutting spacing increases to a large value, such as $20 \mathrm{~mm}$ in this paper.

\subsection{Influence of cutting depth on specific energy}

Fig. 11 depicts the relationship between specific energy and cutting depth. When the value of the cutting spacing is $10 \mathrm{~mm}, 15 \mathrm{~mm}, 20 \mathrm{~mm}$ and $25 \mathrm{~mm}$, the specific energy decreases nonlinearly with the increase of the cutting depth, but the rate of decrease gradually slows as the value of the cutting depth is more than $12 \mathrm{~mm}$. It indicates that the cutting depth can not improve the cutting efficiency effectively

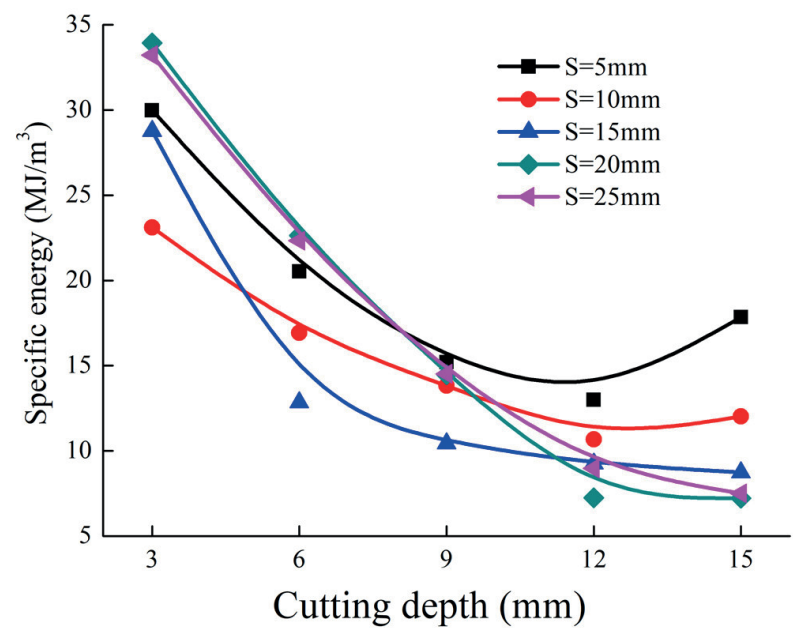

Fig. 11 The relationship between specific energy and cutting depth 
when the cutting depth increases to a certain extent. However, as described in Section 3.2 that the cutting force increases linearly with the increase of cutting depth when the value of cutting spacing varies from $10 \mathrm{~mm}$ to $25 \mathrm{~mm}$. Therefore, considering the comprehensive effects of cutting force and cutting efficiency, the cutting depth should be controlled at about $12 \mathrm{~mm}$ that corresponds to a relatively high cutting efficiency and a relatively low cutting force. In the case that the cutting spacing equals to $5 \mathrm{~mm}$, the specific energy first increases and then decreases with the increase of the cutting depth. The lowest specific energy, $12.99 \mathrm{MJ} / \mathrm{m}^{3}$, is achieved when the cutting depth is $12 \mathrm{~mm}$. This result can be explained by the fact that the rock cut by cutter has broken excessively since the oversized cutting depth, $15 \mathrm{~mm}$, accompanied with little cutting spacing, $15 \mathrm{~mm}$, is adopted, resulting in strong interaction between adjacent cutting grooves, and additional energy consumption that corresponds to a high specific energy.

\subsection{Influence of cutting spacing on specific energy consumption}

Variation in specific energy with a change in cutting spacing is plotted in Fig. 12. On the whole, for a given cutting depth, the specific energy shows a trend of decreasing first and then increasing to a high level with the increase of the cutting spacing. It implies that there exists an optimal cutting spacing to achieve the highest cutting efficiency corresponding to the lowest specific energy for a giving cutting depth. The values of the optimal cutting spacing are about $10 \mathrm{~mm}, 13 \mathrm{~mm}, 15 \mathrm{~mm}, 20 \mathrm{~mm}, 24 \mathrm{~mm}$ when the values of cutting depth are $3 \mathrm{~mm}, 6 \mathrm{~mm}, 9 \mathrm{~mm}, 12 \mathrm{~mm}, 15 \mathrm{~mm}$, respectively. It can be explained that, for a given cutting depth, the rock ridge is extensively broken into small and thin chips when the cutting spacing is too narrow, so high cutting energy is consumed to produce additional crushing surface of the rock. When the cutting spacing is too large, the rock ridge between adjacent cutting grooves can not be detached by the cutters, and the big and effective rock chips can not be produced, causing an increase in specific energy. However, when the cutting spacing is proper that can well match with the cutting depth, the rock ridge can be cut away properly, and the thick and large rock chips can be formed with the minimum specific energy. In this sense, an optimum cutting spacing for the pre-cutting machine cutter can be designed to adapt the actual cutting conditions based on test results. Additionally, it should be pointed out that the optimal cutting spacing has an increasing trend with the increase of the cutting depth, as shown in Fig. 12.

\subsection{Influence of cutting spacing/cutting depth on specific energy consumption}

The optimum ratio of cutting spacing to cutting depth $(S / D)$ is the dimensionless ratio at which the cutting operation gives the minimum specific energy values. Bakar and Gertsch [15] pointed out that the optimal $S / D$ of a pointed tool is between 1.5 and 3. Balci and Bilgin [26] noted that the optimal $S / D$ of a drag cutter is between 1 and 5 . Cho et al. [8] stated that the optimal $S / D$ of a disc cutter is between 10 and 20 .

Fig. 13 shows the relationship between specific energy and $S / D$ for the pre-cutting machine cutter. When the value of the $S / D$ is more than 2 , the specific energy is generally high that corresponds to relatively low cutting efficiency for the pre-cutting machine cutter. It is mainly caused by the fact that the interaction between adjacent cutting grooves is weak when $S / D$ is in this range, and thus adjacent cuts of the pre-cutting machine cutter can

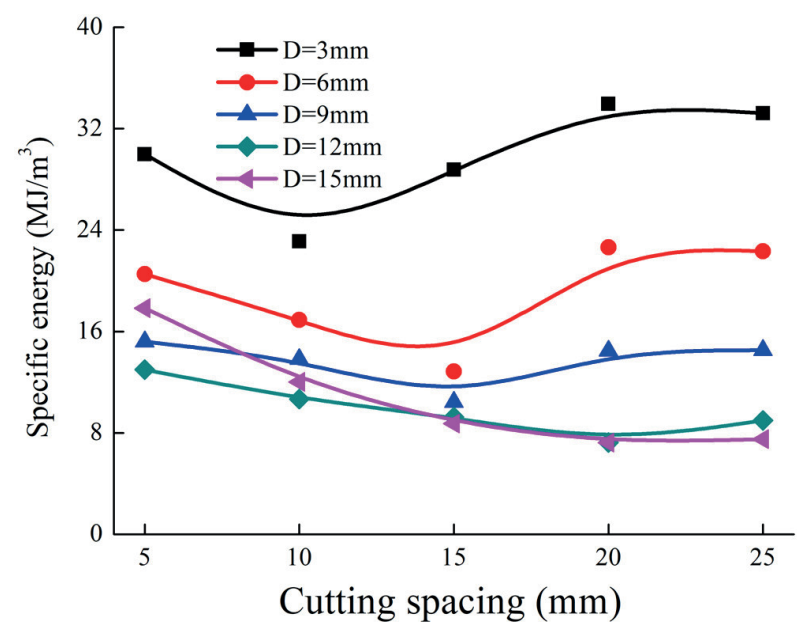

Fig. 12 The relationship between specific energy and cutting spacing

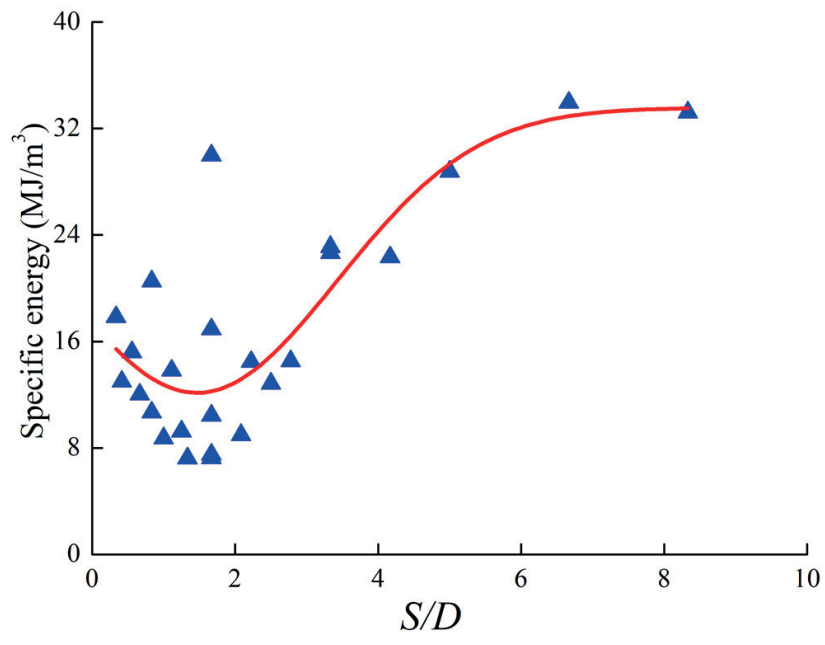

Fig. 13 The relationship between specific energy and $S / D$ 
not collaborate to cut rock. When the $S / D$ is less than 1 , the specific energy is also reached at a relatively high value represented low cutting efficiency. It can be explained that the interaction between adjacent cutting grooves is too strong when the value of $S / D$ varies in this range, leading to rock breaking excessively and an increase in cutting energy. When the $S / D$ changes between 1 and 2 , the specific energy of the pre-cutting machine cutter keeps at a relatively low value accompanied with large and thick rock chips, as stated in Section 3.5. Therefore, when designing the cutter layout of the pre-cutting machine and carrying out the construction of cutting, it is necessary to control $S / D$ within 1 2 to improve the cutting efficiency.

To illustrate the relationship between specific energy and $S / D$ clearly, two kinds of typical cutting states at different $S / D$ are shown in Fig. 14. As shown in Fig. 14(a), the cutting depth is $3 \mathrm{~mm}$, the cutter spacing is $15 \mathrm{~mm}$, and the $S / D$ is 5 which is far more than 2 . There is no obvious interaction between the adjacent cutting grooves and the rock ridge can be found obviously, causing a high specific energy of the pre-cutting machine cutter. As shown in Fig. 14(b), the cutting depth is $6 \mathrm{~mm}$, the cutter spacing is $5 \mathrm{~mm}$, and the $S / D$ is 0.83 which is less than 1 . Under this circumstance, the rock between two cuttings breaks excessively and the cutting efficiency is also relatively low.

\section{Discussion and application}

According to the study in Section 3.4, when the cutting depth exceeds $12 \mathrm{~mm}$ for the pre-cutting machine cutter, the increase of cutting depth cannot improve the cutting efficiency significantly, but will greatly increase the cutting force. Therefore, the cutting depth should be controlled at

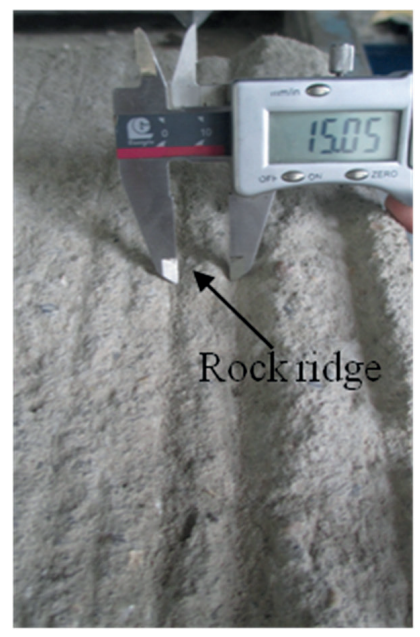

(a) $\mathrm{S} / \mathrm{D}=5$

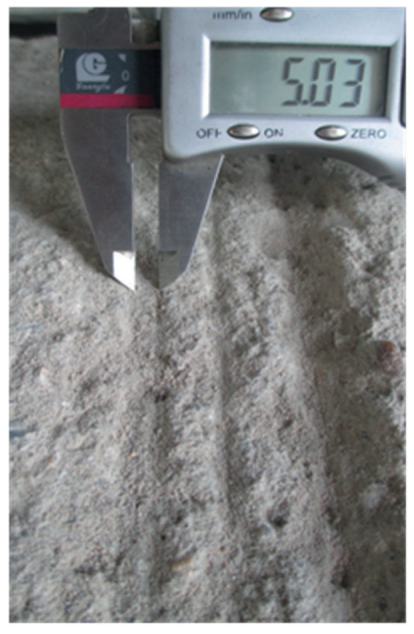

(b) $\mathrm{S} / \mathrm{D}=0.83$
Fig. 14 Two kinds of cutting states at different S/D about $12 \mathrm{~mm}$. Based on the conclusion in Section 3.5, the optimum cutting spacing is approximately $20 \mathrm{~mm}$ when the cutting depth is $12 \mathrm{~mm}$. Therefore, the cutter layout plan of the pre-cutting machine can be obtained, as shown in Fig. 15. Cutters are lined up orderly along the cutting direction, the row spacing $(R S)$ is designed at $80 \mathrm{~mm}$ to remove fragments more easily, and the adjacent cutting spacing $(C S)$ is designed at $20 \mathrm{~mm}$ to guarantee the cutting efficiency. The cutters are symmetrically arranged to ensure the balance of cutter forces. Only one cutter is arranged to slot in the first row, and its force and wear will be relatively larger than those of other cutters. To overcome this problem, another cutter is arranged to reduce the wear of the middle cutters in the middle position of the sixth row that has three cutters, as shown in Fig. 15(a).

It is worth noting that, to increase the width of the groove, the cutters laid in the fifth and sixth rows should be inclined to ensure the cutter head can cut the rock outside the chain plate and increase the width of the cutting groove. The cutter height should also be highly consistent with the cutter height of the front rows and the CS is also maintained at $20 \mathrm{~mm}$. Then, every six rows of cutters are arranged in sequence until the entire chain plate is covered.

The layout plan of the pre-cutting machine cutter mentioned above is adopted in the manufacturing of the pre-cutting machine by China Railway Construction Heavy Industry, as shown in Fig. 16(a). This pre-cutting machine is composed of cutters (1), a front column (2), a

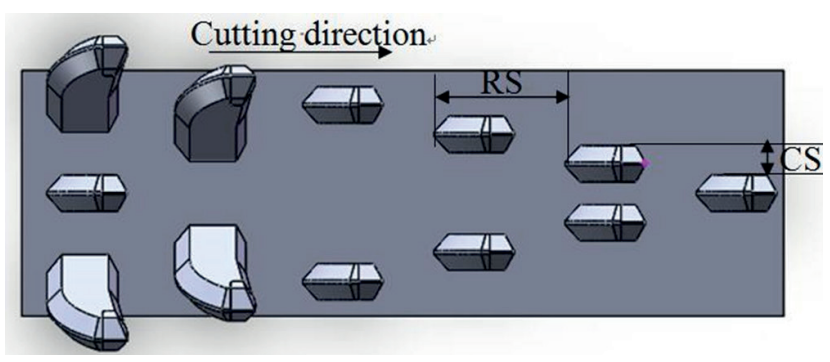

(a) Layout plan in two-dimension

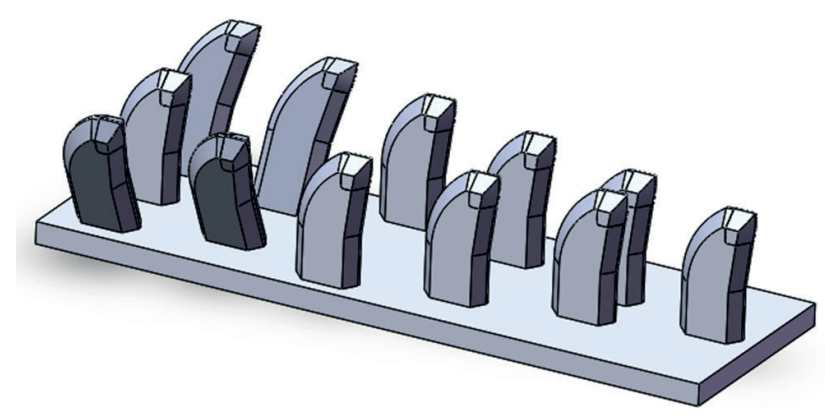

(b) Layout plan in three-dimension

Fig. 15 Layout plan of cutters 
cutter beam (3), a driver's cab (4), an electrical system (5), a rear pillar (6), a frame (7), a walking mechanism (8), and other components. This pre-cutting machine has been used to cut tunnel in China, as shown in Fig. 16(b). The engineering results show that the pre-cutting machine with the cutter layout plan mentioned above has high cutting efficiency and cutting reliability, which is very suitable for cutting this kind of rock ground.

\section{Conclusions}

In this paper, the rock cutting tests by the pre-cutting machine cutter under different working parameters are carried out and a kind of layout plan of cutters is proposed. The main conclusions can be drawn as follows:

1. The formation of rock chips induced by the pre-cutting machine cutter is dominated by tensile failure. The cutter forces in three directions show fluctuating change during cutting process and the cutting force is larger than the normal force and side force which is mainly responsible for the rock breaking.

2. The cutting force increases with the increase of cutting depth and cutting spacing generally. However, for a little value of cutting spacing, the increase of cutting depth has a negative effect on the increase of the cutting force when the cutting depth is achieved at a relatively high value. Furthermore, for a given cutting depth, the cutting force will keep at an approximate constant rather than continuous increase with the increase of the cutting spacing when the cutting spacing increases to a relatively large value, at which the rock ridge can not be cut away.

3. The specific energy presents a decreasing trend with the increase of cutting depth. But the rate of decrease gradually slows when the cutting depth is more than $12 \mathrm{~mm}$. For a given cutting depth, there exists an optimal cutting spacing to achieve the highest cutting efficiency, and the optimal cutting spacing increases with the increase of cutting depth.

\section{References}

[1] Bougard, J. F. "The mechanical pre-cutting method", Tunnelling and Underground Space Technology, 3(2), pp. 163-167, 1988. https://doi.org/10.1016/0886-7798(88)90093-4

[2] van Walsum, E. "Mechanical pre-cutting, a rediscovered tunneling technique", Rock Mechanics and Rock Engineering, 24(2), pp. 65-79, 1991

https://doi.org/10.1007/BF01032499

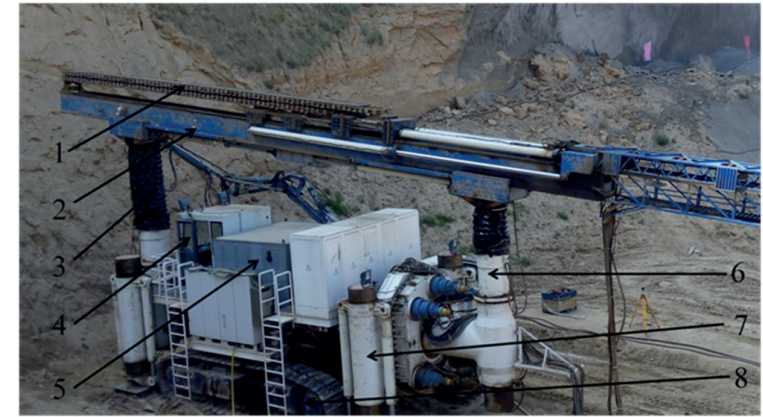

(a) Pre-cutting machine

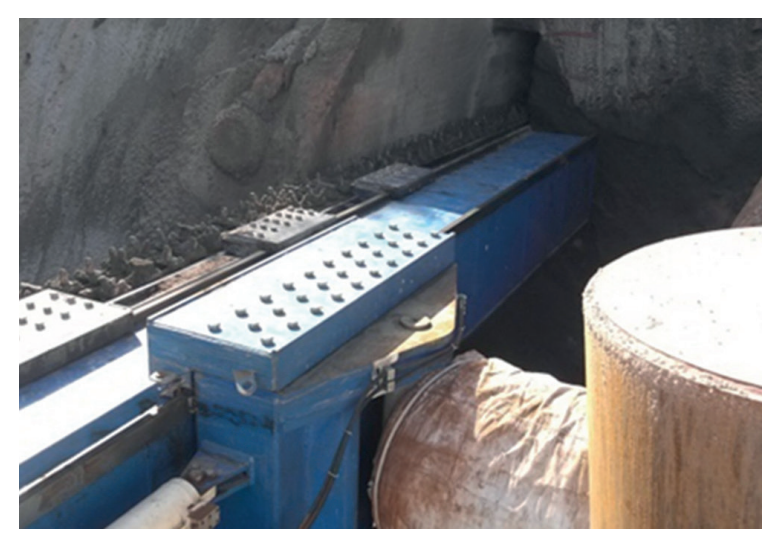

(b) The application of pre-cutting machine

Fig. 16 The pre-cutting machine and its application

4. For the pre-cutting machine cutter, the cutting efficiency will keep at a relatively high value when the ratio of cutting spacing to cutting depth ranges between 1 and 2. A new kind of layout plan for pre-cutting machine cutters is proposed based on the comprehensive consideration of cutting force and specific energy which is applied in the actual manufacturing of the pre-cutting machine.

\section{Acknowledgment}

This research reported in this paper is supported by the National Natural Science Foundation of China (Grants No. 51905550 and 51907062) and the National Key Technology Support Program of China (Grant No. 2013BAF07B06).

[3] Wang, X., Liu, W., Zhao, B., He, M., Li, K. "Pre-cutting Method and its Key Techniques in Application", Modern Tunnelling Technology, 48(3), pp. 22-34., 2011. https://doi.org/10.3969/j.issn.1009-6582.2011.03.004

[4] Xia, Y., Zhang, X., Tan, Q., Wu, C., Qian, C., Liu, J. "Study on properties of cutting rock and soil medium by pre-cutting cutters", Modern Tunnelling Technology, 54(6), pp. 166-173, 2017. https://doi.org/10.13807/j.cnki.mtt.2017.06.022 
[5] Tonon, F. "Sequential excavation, NATM and ADECO: What they have in common and how they differ", Tunnelling and Underground Space Technology, 25(3), pp. 245-265, 2010.

https://doi.org/10.1016/j.tust.2009.12.004

[6] Du, L., Wang, X., Liu, W. "On the mechanism of controlling deformation of weak surrounding rock with a pre-arch", Modern Tunnelling Technology, 51(1), pp. 62-69, 2014.

https://doi.org/10.13807/j.cnki.mtt.2014.01.012

[7] Hao, Y. J., He, M. D., Zhao, K., Wang, X. Y. "Detailed Analysis of Structure and Model Design for Construction Machinery of Mechanical Pre-Cutting Method", Journal of North University of China: Science and Technology, 43(1), pp. 86-92, 2013.

https://doi.org/10.3969/j.issn.1673-3193.2013.01.018

[8] Cho, J. W., Jeon, S., Jeong, H. Y., Chang, S. H. "Evaluation of cutting efficiency during TBM disc cutter excavation within a Korean granitic rock using linear-cutting-machine testing and photogrammetric measurement", Tunnelling and Underground Space Technology, 35 , pp. 37-54, 2013

https://doi.org/10.1016/j.tust.2012.08.006

[9] Qi, G., Zhengying, W., Hao, M. "An experimental research on the rock cutting process of the gage cutters for rock tunnel boring machine (TBM)", Tunnelling and Underground Space Technology, 52, pp. 182-191, 2016.

https://doi.org/10.1016/j.tust.2015.12.008

[10] Qi, G., Zhengying, W., Hao, M., Qiao, C. "Numerical and experimental research on the rock-breaking process of tunnel boring machine normal disc cutters", Journal of Mechanical Science and Technology, 30(4), pp. 1733-1745, 2016

https://doi.org/10.1007/s12206-016-0329-9

[11] Zaré Naghadehi, M., Mikaeil, R. "Optimization of Tunnel Boring Machine (TBM) Disc Cutter Spacing in Jointed Hard Rock Using a Distinct Element Numerical Simulation", Periodica Polytechnica Civil Engineering, 61(1), pp. 56-65, 2017. https://doi.org/10.3311/PPci.9521

[12] Liu, J., Cao, P., Han, D. "Sequential Indentation Tests to Investigate the Influence of Confining Stress on Rock Breakage by Tunnel Boring Machine Cutter in a Biaxial State", Rock Mechanics and Rock Engineering, 49, pp. 1479-1495, 2016. https://doi.org/10.1007/s00603-015-0843-6

[13] Liu, J., Wang, J. "The effect of indentation sequence on rock breakages: A study based on laboratory and numerical tests", Comptes Rendus Mécanique, 346(1), pp. 26-38, 2018. https://doi.org/10.1016/j.crme.2017.11.004

[14] Zhang, X., Xia, Y., Tan, Q., Wu, D. "Comparison Study on the Rock Cutting Characteristics of Disc Cutter under Free-face-assisted and Conventional Cutting Methods", KSCE Journal of Civil Engineering, 22(10), pp. 4155-4162, 2018. https://doi.org/10.1007/s12205-018-0577-6

[15] Bakar, M. Z. A., Gertsch, L. S. "Evaluation of saturation effects on drag pick cutting of a brittle sandstone from full scale linear cutting tests", Tunnelling and Underground Space Technology, 34, pp. 124 134, 2013.

https://doi.org/10.1016/j.tust.2012.11.009
[16] Xia, Y., Xue, J., Zhou, X. "Rock fragmentation process and cutting characteristics on shield cutter", Journal of Central South University: Science and Technology, 42(4), pp. 954-959, 2011.

https://doi.org/1672-7207(2011)04-0954-06

[17] Copur, H., Bilgin, N., Balci, C., Tumac, D., Avunduk, E. "Effects of Different Cutting Patterns and Experimental Conditions on the Performance of a Conical Drag Tool", Rock Mechanics and Rock Engineering, 50(6), pp. 1585-1609, 2017. https://doi.org/10.1007/s00603-017-1172-8

[18] Qiao, S., Xia, J., Xia, Y., Liu, Z., Liu, J., Wang, A. "Establishment of Coal-rock Constitutive Models for Numerical Simulation of Coal-rock Cutting by Conical Picks", Periodica Polytechnica Civil Engineering, 63(2), pp. 456-464, 2019. https://doi.org/10.3311/PPci.13084

[19] Xuefeng, L., Shibo, W., Shirong, G., Malekian R., Zhixiong, L. "Investigation on the influence mechanism of rock brittleness on rock fragmentation and cutting performance by discrete element method", Measurement, 113, pp. 120-130, 2018. https://doi.org/10.1016/j.measurement.2017.07.043

[20] Jeong, H., Jeon, S. "Characteristic of size distribution of rock chip produced by rock cutting with a pick cutter", Geomechanics and Engineering, 15(3), pp. 811-822, 2018. https://doi.org/10.12989/gae.2018.15.3.811

[21] Wang, S., Li, X., Du, K., Wang S. "Experimental investigation of hard rock fragmentation using a conical pick on true triaxial test apparatus", Tunnelling and Underground Space Technology, 79, pp. 210223, 2018. https://doi.org/10.1016/j.tust.2018.05.006

[22] Li, X., Wang, S., Wang, S. "Experimental Investigation of the Influence of Confining Stress on Hard Rock Fragmentation Using a Conical Pick", Rock Mechanics and Rock Engineering, 51, pp. 255277, 2018. https://doi.org/10.1007/s00603-017-1309-9

[23] Xia, Y., Shi, Y., Lin, L., Zhang, Y., Tan, Q., Yang, Y. "Experimental Evaluation of Fragments from TBM Disc Cutting under Different Load Cases", Periodica Polytechnica Civil Engineering, 62(3), pp. 746-756, 2018. https://doi.org/10.3311/PPci.11961

[24] Pan, Y., Liu, Q., Liu, J., Liu, Q., Kong, X. "Full-scale linear cutting tests in Chongqing Sandstone to study the influence of confining stress on rock cutting efficiency by TBM disc cutter", Tunnelling and Underground Space Technology, 80, pp. 197-210, 2018. https://doi.org/10.1016/j.tust.2018.06.013

[25] Rojek, J., Oñate, E., Labra, C., Kargl, H. "Discrete element simulation of rock cutting", International Journal of Rock Mechanics and Mining Sciences, 48(6), pp. 996-1010, 2011. https://doi.org/10.1016/j.ijrmms.2011.06.003

[26] Balci, C., Bilgin, N. "Correlative study of linear small and fullscale rock cutting tests to select mechanized excavation machines", International Journal of Rock Mechanics and Mining Sciences, 44(3), pp. 468-476, 2007. https://doi.org/10.1016/j.ijrmms.2006.09.001 